\title{
A Comprehensive Survey on the Impact of Renewable Energy Sources in Power System Operation and Control
}

\section{Vinay Kumar Tatikayala ( $\nabla$ vinayktkl21@gmail.com )}

Madhav Institute of Technology and Science https://orcid.org/0000-0002-5822-7879

\section{Shishir Dixit}

Madhav Institute of Technology and Science

\section{Research Article}

Keywords: Renewable energy sources, power system, solar energy, wind energy, artificial intelligence

Posted Date: March 30th, 2021

DOI: https://doi.org/10.21203/rs.3.rs-338842/v1

License: (c) (i) This work is licensed under a Creative Commons Attribution 4.0 International License.

Read Full License 


\title{
A COMPREHENSIVE SURVEY ON THE IMPACT OF RENEWABLE ENERGY SOURCES IN POWER SYSTEM OPERATION AND CONTROL
}

\author{
Vinay Kumar Tatikayala ${ }^{* 1}$, Shishir Dixit ${ }^{2}$ \\ ${ }^{1}$ Research Scholar, Department of Electrical Engineering, Madhav Institute of Technology and \\ Science, Madhya Pradesh, India. \\ ${ }^{2}$ Professor, Department of Electrical Engineering, Madhav Institute of Technology and Science, \\ Madhya Pradesh, India.
}

Corresponding Author Mail ID: vinayktk121@gmail.com

\begin{abstract}
The concern for huge increasing electricity demand, fossil fuel depletion, developed infrastructure reliability, carbon footprint reduction insisted the power utility companies to uptake RES (Renewable Energy Sources). The improved adoption of RES like wind energy and solar energy into the prevailing transmission and distribution networks led to several problems. These problems could be rectified by optimizing the power system parameters like frequency response, inertia, stability, battery usage, efficiency and power loss. This review hence provide a comprehensive analysis on the impact of renewable energy sources like wind and solar energy on power system operation and control in accordance with the major findings of the existing works. This review highlights the difficulties in the installation of solar and wind power with adoptable solutions. The challenges of power systems regarding the encoding of non-linearized function could be rectified by AI (Artificial Intelligence). The paper also insists the importance of artificial intelligence algorithm in the optimization of power system parameters. Artificial intelligence methods is useful for resolving various issues in power systems such as control, scheduling, forecasting etc. Few artificial algorithms such as Atom search optimization, Particle swarm optimization, Salp swarm optimization were investigated in this review for improving the performance of the power system. In spite of optimization analysis, the paper investigate various storage system types for improving the power system in accordance with cost, application and operation characteristics. Proper understanding of these systems is necessary for the future designing and hence through revision of state of art characteristics has been performed in this paper.
\end{abstract}

Keywords: Renewable energy sources, power system, solar energy, wind energy, artificial intelligence.

\section{INTRODUCTION}

Electrical energy has been regarded as a major industrial source for transmitting and generating power over large distances. The industries are facing challenging issues particularly in the designing of future power systems that delivers huge amount of electricity[1]. The growing electricity demand draws the attention of recent research to focus on renewables. Such growth has been accelerated by the various power system parameters such as frequency response, inertia, battery usage, stability, power loss and efficiency. Further electricity demands and RES must be balanced for maintaining safe, stabilized and dependable operation[2]. Hence it is required to analyse and investigate the impacts of RES in power system operation and control on the basis of the following directions.

- It is significant to determine the factors associated with the transmitting and distributing operations[3].

- The importance of establishing a power reserve which balances the consumption and production must be focused.

- Determination of a maximum RES which could be integrated into the power source with optimized power control parameters.

Such kind of power system analysis by traditional methods seems to be more complex due to difficult, versatile and huge amount of information utilized in estimation and diagnosis.

Further accuracy and computational time period must be focused because of the vast and 
extensive data handling[4]. Integrating several renewable energy sources in power-systems can decrease the amount of conventional generation units, which provides inertia response as well as frequency control. This kind of situation needs an optimized and conservative power system with the aid of AI (Artificial Intelligence)[5]. AI methods might not require any kind of significant knowledge of the power system control model. Moreover they possess the ability to handle inappropriate situations such as corrupted data, missing information etc [6]. These techniques are also fault tolerant, robust, adaptive, generalizable and fast. Hence the paper focused on the optimization the power control parameters such as inertia, power loss, frequency response, stability, efficiency and battery usage in the integrated environment with RES with various AI algorithms.

\section{POWER SYSTEM}

Electrical power systems referred as power systems could be described as a network of electric devices for generating, transmitting and distributing electrical power[7]. The main objective of power system control is the maintenance of constant electrical supply in an acceptable quality against several disturbances[8]. Such disturbances might be categorized into large scale and small scale disturbances[9]. Power quality issues are established as frequency deviation, distorted current and voltage waveforms that leads to destruction or failure of the customer equipment[10]. In addition, the power system must offer a reliable, secure and uninterrupted energy flow with sinusoidal voltage at the defined frequency and magnitude level[1]. In general poor quality of power might result in high power loss, undesirable equipment behaviour and intrudance with nearby communicating lines[11]. Hence the paper analyses the role of power system parameters in its operation and control[12]. The parameters of the power systems such as frequency response, inertia, stability, efficiency and power-loss are investigated[13].

\section{Inertia}

Generally, in power-systems, inertia play a significant role in the maintenance of reliability and stability of system by stabilizing the variations in frequency[14]. The conventional synchronous generation sources were displaced by the renewable energy sources that have no intrinsic inertia[15]. Further, several studies examined the impacts of the reduced inertia on various aspects of dynamic stability of the power-systems like oscillatory modes, frequency response and stability[16]. Also, compared the outcomes obtained by inertia reduction technique of the RES with other techniques, where the inertia constant is decreased for all the synchronous generators. In such way, the following articles comprehensively describes about the inertia in power systems and its impacts.

This study [17] presented detailed review on the VI (virtual inertia) based inverters in the modern power systems. Further, the transition from SG (synchronous generator) based traditional power generation to the converter based RES (renewable energy sources) depreciates the frequency stability of powersystems because of intermittency of PV (photovoltaic) as well as wind generation. Moreover, unlike the traditional power generation, inadequate inertia will be the major drawback for interfacing the renewable energy sources with electrical gird through powerelectronic converters. In recent years, several researchers have addressed about these problems by imitating the behaviour of synchronous generators through PWM (pulse width modulation) controller that are linked to the traditional inverter systems. Hence, these systems are called as the virtual inertia (VI) based inverters that incorporated VSM (virtual synchronous machine), synchronverter as well as VSG (virtual synchronous generator).

Due to the rapid increase in usage of power converter based RES (renewable energy sources), the system inertia in the interconnected power-systems will be substantially reduced, thereby increasing vulnerability of power-systems because of instability of the systems. In order to overcome these issues, this study [18] suggested a novel application of VI control for the improving the frequency stability of interconnected powersystems because of the higher penetration levels of renewable energy sources. Further, the derivative control method was introduced to high level applications of VI emulation. Therefore, the suggested VI control loop possess second order characteristics simultaneously enables inertia emulation as well as damping into interconnected powersystems, thereby enhancing the resiliency and frequency stability. Additionally, the study performed trajectory sensitivities for analysing 
the impacts of VI control parameters on system stability.

The (renewable energy sources) RES are usually connected to power grid through the power-electronic converters. The higher penetration of RES into power grid might result in more instability in frequency and voltage. These problems are due to the avoidance of inherent characteristics of the SG (synchronous generators). In order to overcome these issues, this study[19] presented a power based control method on the basis of DSC (double synchronous controller) to interface the converter between power grid as well as RES that includes active reactive power-based dynamic equations. By the suggested method, this study performs decoupled controlled technique, from which a stable operation was guaranteed by the study while integrating large scale RES. Additionally, this study performed the analysis in MATLAB and verified the proficiency of the suggested method.

In recent years, due to the rapid increase of VRE (variable renewable energy) penetration in power systems, there is a decrement in the synchronous machines in the European powersystems. Further, the appropriate inertia levels for assuring the stability of systems, this study [20] examined the impacts of various levels of minimum inertia constraints in Europe as well as in every synchronous areas. The study simulated 2 scenarios with different decarbonisation aims for 2030 by utilizing economic dispatch as well as unit commitment model. Moreover, the findings of the study depicted that, increasing levels of inertia constrains increases the cost of total generation. And, when the inertia constrains applied to contrasting scenario, the study observed $49 \%$ of decrement on the emission of carbon dioxide.

\section{Inertia of conventional power system}

In conventional power systems, majority of the power is generated hydroelectric, coal and nuclear power. Further, the common element used in the power plants is synchronous generators. The kinetic energy which is stored in rotating parts of synchronous generators is the major property for the system stability as well as frequency dynamics[21]. Moreover, the inertia contribution is an impressive and feature of synchronous generators. In this manner, the synchronous generator maintains the synchronism as well as prevents the grid collapse. The inertia of synchronous generator is given as the following,

$$
J=\int r_{S G}^{2} d m=r_{S G}^{2} m
$$

From the above equation, it is observed that $r_{S G}$ is known as radius of rotating part of synchronous generators, whereas $m$ is known as the mass.

The total inertia in conventional power systems could be described as the resistance as a form of the kinetic-energy for compensating the variations on frequency. Therefore, the short term energy under the load-fluctuations is known as inertia. Moreover, the kinetic energy required during the power-imbalance can be expressed as,

$$
\Delta E_{K E}=\int\left(P_{G}-P_{L}\right) d t
$$

From the above equation, it is observed that $P_{G}$ is generated power and $P_{L}$ is the load power.

Impact of renewable energy sources on the inertia of power system

The conventional power systems could contribute the inertia to power systems. Generally, inertia assists to limit the rate of change of frequency (ROCOF) and the contingency event. However, in the future of power systems, the loads as well as the Renewable energy sources are integrated to the grid via power-electronic converters. Therefore, the inertia of future power systems will be significantly reduced when compared to the conventional power systems. Consequently, the frequency as well as the rate of change of frequency will increase of contingency event arises[21]. Hence, the grid operators cannot maintain the stability of the system with only traditional synchronous generators. The instability problems occurs if the renewable energy system penetration level is equal of more than the synchronous generator's capacity. Additionally, the impact of the damping and lower inertia influences the performance of the grid, thereby leads to the frequency instability issues[22].

\section{Frequency response}

Conventionally, the network of power-systems rely on the heavy SGs (synchronous generators) that are fuelled with the fossils fuel for generating power. The rotating frequency of generator is directly coupled with the frequency 
of power systems, thus this disturbance on power system network would have an significant influence in SG's rotor[23].

The frequency of the system serves as the primary indicator for power-balance between total load as well as total generation in power systems[24]. Further, when load/generation imbalance occurs, and the SG will absorb kinetic energy from power systems for normalising the imbalance issue, thereby resulting in frequency change[25]. When renewable energy sources replacing with the SGs (synchronous generators), the RES should participate in initial response for the low frequency events for combating the decline in the online SG[26]s.

The relevant integration of the wind power to power grid was involved as remarkable impact on the operation of power systems, specifically in terms of reliability as well as security because of inherent loss of inertia. The frequency control is most appropriate solution for improving the stability of the system. With respect to the grid stability as well as frequency response analysis, the study analysed the frequency response for the hypothetical imbalance between the range $5 \%$ to $20 \%$. This study [27] suggested a realistic system for evaluating the frequency deviations by incorporating the integration of high wind power. From the experimental analysis, the study provided several influences from the wind FC (frequency control) depending upon the integration of wind-power and inertia reduction.

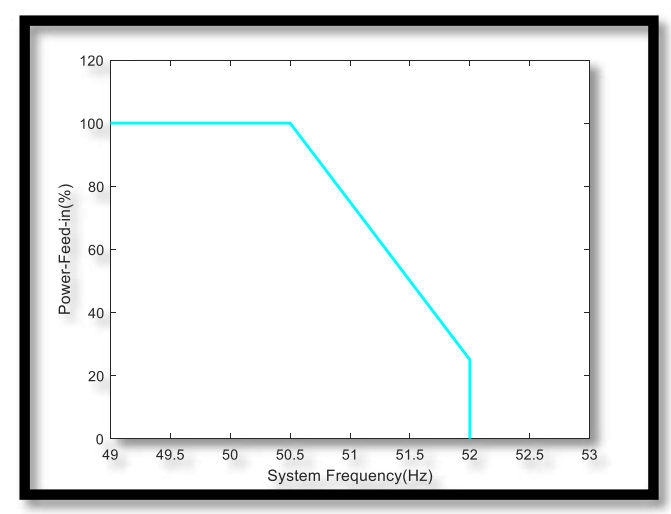

Figure 1. Power curtailment during the overfrequency for renewable power plants

When power system's frequency exceeds $51.5 \mathrm{~Hz}$ more than four seconds, the renewable power plants are discontinued from power systems. From the figure 1, it is understood that, during lower system frequency i.e. $\mathrm{f}<50 \mathrm{~Hz}$, the renewable power plants produce about $100 \%$ of availability power. Thus, there is no power reserved for stabilizing drop in frequency during the low-frequency. Further, the SGs (synchronous generators) provides the inertial response for combating drop in frequency, thereby providing additive power from stored kinetic energy in rotating mass. When renewable energy sources replacing with the SGs (synchronous generators), the RES should participate in initial response for the low frequency events for combating the decline in the online SGs.

\section{Stability}

The major purpose to develop MGs (micro grids) is for facilitating integration of RES (renewable energy sources) in power systems. The renewable energy sources are connected to grid through power-electronic inverters. Since, there are several types of renewable energy sources integrated to electrical power systems, the future of power systems would have many IBGs (inverter based generators) rather than the synchronous machines. As the inverter based generators have substantial variations in the characteristics when compared to the SGs, specifically considering about the inertia as well as the capability for providing reactive power. This study [28] is conducted on stability of power-systems with incorporating inverter based generators. Further, this study examined the issues on the voltage stability of the micro grids in the power-systems. This study also presented a comprehensive review regarding the voltage stability of power-systems. The future analysis deals with developing more approaches in this particular field.

\section{Power loss}

The VRE (variable renewable energy) sources are adding more fluctuations to the power system. Further, the required types as well as the capacities of curtailment amount, balancing measures as well as the cost related to the system integration must be assessed to advise the policy makers. Several studies neglected storage from CSP (concentrated solar-power). This study [29] provided insights about the need for the backup capacity as well as grid by examining the integrated markets in Europe, thereby allowing for additive long term and short term storage and taking into account the concentrated solar power as dispatchable 
backup. The renewable energy mix system model has been introduced and implemented for accessing the hourly dispatch and capacity expansion at different levels of wind power and photovoltaic penetration. Moreover, the model outcomes represented that the integration of temporal and spatial balancing measures, which enables the wind supply as well as net photovoltaic shares $70 \%$ and $60 \%$ of annual demand. Finally, the study stated that the utilization of storage as well as grid can keep the curtailments less than $20 \%$. Additionally, the study determined that the variable renewable energy has huge impacts on the least-cost allocation of the power plants.

\section{Efficiency}

This study [30] described the benefits of RES throughout world in power generation. The renewable energy has significant scope in the power systems. Further, the RES acts as major powerhouse of the micro grids. The micro grids are small network of the power-systems with DG (distribution generation) units, that are connected in parallel. Also, the challenges involved in the integration of renewable energy sources in power systems are briefly described in the study. Moreover, the varied nature of the distribution generation produces the frequency as well as voltage deviations. Finally, the study examined the micro grid performance against various scenarios. Additionally, the micro grid's voltage is controlled by utilizing various controllers, and the outcomes were also examined. The study examined the controller performance by using Simulink/MATLAB.

\section{RENEWABLE SOURCES}

ENERGY

In an interconnected power-system, the frequency stability is considered as the major issue for the system operators. Further, frequency oscillations within the power system is denoted as the unbalance between load demand and generation that needs to be in control. A higher penetration of RES (renewable energy sources) in power system increases the uncertainties to the parameters and brings numerous technical difficulties[5]. Initially, it was demonstrated that the QODA algorithm is improved optimization method when compared to non-conventional and conventional ways. The suggested control strategy was applied for tuning PID controller parameters in presence of renewable energy sources.
The demand for world-wide electricity is gradually raising, thereby making use of wind and solar energy sources that reduces the adverse environmental impacts. The variable energy source has a significant role in global energy, which includes the generating capacity. This study [31] presented the challenges of integrating VRE (variable renewable energy) in accordance to energy capacity as well as power capacity of the stationary storage technology. From the analysis, the study stated that the energy storage regulations as well as the market developments that motivates the increased utilization of energy storage system is significant for successful integration of wind and solar energy. Also, the study proves that, apart from energy capacity, the power capacity of the storage system is the major factor for efficient integration of VRES.

This article [32] observed the impacts of penetration as well as computed maximum penetration of VRE (variable renewable energy) power plants for the time period 2019 to 2023, specifically for solar power-plants. Further, the penetration of solar power-plant for JavaeBali grid should be employed in certain areas because of the limited technical capabilities of the existing systems. The variables for determining the maximum penetration of variable renewable energy are the properties of the thermal generation units like mechanism of primary energy conversion, minimum load as well as ramping capability. From the analysis, the outcomes depicted that the penetration of variable renewable energy at 5000MWp capacity increases the requirement of grid remapping.

\section{Solar energy}

Renewable energy sources (RES) play a significant role in recent years for assisting traditional power systems. This study [33] presented a performance analysis of the integrated hybrid solar photovoltaic, diesel generator as well as fuel cell power system with BESS or SCESS (battery energy storage system) or (super-capacitor energy storage system). Further, this study utilized HOMER pro software for simulating HES (hybrid energy system) on the basis of energy consumption. The simulation outcomes depicted that, when utilizing SCESS as energy storage system increased the overall performance of the system. Additionally, the hybrid energy system with super-capacitor energy storage system has $68.1 \%$ of renewable fraction. Finally, the study 
stated that the reduction of greenhouse gas for hybrid energy system with super-capacitor energy storage system was $83.2 \%$.

Using both the solar as well as wind energy can cause a complementarity behaviour by diminishing the variable and inherent characteristics. Solar and wind energies are eminent RES (renewable energy sources), and several countries are investing in RES and also certain studies have investigated in this topic, in such way study [34] utilized wind as well as solar power for the grid integration in large scale. The integrated usage of solar and wind power in several regions results in wellbalanced power supply that is critical for safety and operability of the electrical grids.

As there are numerous number installations of PV (photovoltaic) around the world, the photovoltaic impacts on the power systems were also rapidly increasing. In this study [35], implications of the high photovoltaic penetration on reliability as well as stability of the power systems' flexibility, stability, harmonics, protection, frequency and voltage were comprehensively reviewed. Further, the study also analysed the factors that contribute to the impacts, and timeframes and levels. The tools as well as models employed in the power systems were also elaborated by the study.

\section{Basic concept of photovoltaic cell}

The photovoltaic (PV) cell is an electric device, which generates electrical-power when it is exposed to the sunlight. Further, the generated electric power is then connected to the suitable load. This photovoltaic technology can become major renewable energy sources with a cost reduction in systems like $\mathrm{AC} / \mathrm{DC}$ inverters, cables, fittings, PV modules and manpower. For the analysis of lower frequency domain, transfer-function model the photovoltaic system is shown as the below mentioned equation. Moreover, the hybrid power-system carries different autonomous generation-systems such as solar PV (photovoltaic), aqua electrolyzer, fuelcell and diesel engine.

$$
G_{p v}(S)=\frac{P_{p v}}{P_{\varnothing}}=\frac{1}{1+T_{p v}}
$$

From the above equation it is understood that, $T_{p v}$ is known as time constant of photovoltaic.

\section{Wind energy}

The contribution of wind farms in improvisation of frequency control while integrating power grid was comprehensively discussed by [36], in which the study suggested an approach of quantifying wind penetration on the basis of power fluctuation amount, which could be filtered by the wind-turbine generators as well as thermal plants. The wind farm uses the droop control and energy control methods for improvisation of frequency regulation. Further, the study used PSO algorithm for obtaining optimum results.

The LFC (load frequency study) of power systems incorporating gas, hydro and thermal based generating units in the existence of windpower plant under various penetrating levels as well as operating models was studied by [37]. Further, the wind-power integration shifted the electricity-grid in transition phase to newer model, in which the wind power-plants participated in every frequency regulation levels.

In order to improvise the frequency-stability in an inter-connected power-system incorporating RES (renewable energy sources), the control actions must be more efficient and robust. This study [38] suggested a novel optimized PID controller (proportional integral derivative) with RFBs (redox flow batteries) for enhancing the LFC (load frequency control) of the power system regarding huge penetration of windpower generation.

In order to achieve clean energy, this study [39] integrated the renewable energy systems such as PV and STPG (solar photovoltaic and solar thermal power generation) in power system. Also, the study investigated the impacts of solar thermal system for load frequency control study of unequal thermal power system.

\section{Solutions}

Even though there are various challenges related to penetration of RES in power systems, there are several solutions, which can provide flexibility for handling these difficulties. Those include balancing the overall variable renewable energy output power via sufficient amount of geotropic diversity when utilizing these variable renewable energy generators. Further, expanding the transmission system will effectively move more power to the regions where the load is significantly required. Moreover, the increased geographic diversity of the variable renewable energy generators as well as the usage of transmission resources will 
be achieved by coordinating with balancing authority as well as the faster interchange intervals.

\section{Recent trends of Renewable energy sources}

The Renewable energy sources (RES) are gaining huge popularity in the mainstream power-systems[13]. The native power systems generally needs some modifications for meeting strong requirements of rapid increase of the electricity consumption, uninterruptable power in urban and rural areas[40]. The renewable energy sources gradually replaces the one way power-transmission, and generally, the RES are small machines, low inertia driven by the sources like waves, hydro, solar as well as wind[41]. These sources are connected near to the load-points for fulfilling the load demands. In recent days, power systems are considered as distributed energy systems with various RES along the automatic control as well as the communication[42]. Several countries started to implement the renewable energy sources in power systems in an integrated environment[43].

Countries like Germany, Ireland and Denmark aggressively implemented the (VRE) variable renewable energy systems as well as operating with the annual variable renewable energy penetration of above $20 \%$ at national level[44]. Furthermore, currently Ireland limits the instantaneous penetration (55\%). And the variable renewable energy provides annual energy of $5 \%$ and $13 \%$ in United States and Europe[45].

The solar energy and wind-power are different from the thermal generators, since they possess uncertain as well as variable power results that are established by the local weather conditions[46]. The conventional generators like gas plants and coal are dispatchable as they change their power for meeting the variations in load.

As more variable renewable energies are implemented into the power systems, the future grid would have several inverter based generators as well as more distributed than existing power system that is dominated by the synchronous generators. Generally, the VRE (variable renewable energy) resources utilize inverters for connecting grids than the synchronous generators.

Implementation of renewable energy sources in power system has massive amount of inverter generators and also it fluctuates between the inverter dominated as well as generator dominated on daily basis.

\section{Impacts of renewable energy sources in power} systems

The study [47] highlighted the future generation of the energy, contributed by the RES (renewable energy sources). Further, the conservative power-plants dischargers the GHG (greenhouse gas) as well as energy crisis that was diminished by the RES (renewable energy sources) of PV (photovoltaic) and wind energies. Moreover, the impact of renewable distributed generation as well as cost of outrage power, calculated by the evaluation of reliability. The requirement of the consumer load with the PV, wind turbines and the electric storage satisfied by the assessment of the distribution system. Further, the study analysed the reliability influence by the suggested method. From the experimental analysis, the results depicted improvised performance.

Similarly, in this study [48] the RES (renewable energy sources) of the mathematical model rely on the meteorological data processing was suggested. Further, the study made a system of photovoltaic wind-energy assessment combined with the pump storage hydro plant. Finally, the study stated that the suggested method had better efficiency than the battery storage systems.

In this article, [13], the reliability of the power systems was increased as well as the dependency was diminished by the RES measures. Further, the conventional micro grid power-systems were improvised as well as the cost of energy was decreased by the photovoltaic, wind turbines and battery storage. The RES based technology has achieved overall better performance.

\section{VARIOUS ALGORITHMS USED FOR OPTIMIZING POWER CONTROL PARAMETRS}

The uncertainties of RES would bring several impacts to the reliability and stability of powersystems. So various studies have implemented different algorithms for improving the overall system stability and performance. In such way, this study [49] suggested a new generationrescheduling algorithm that modifies the generation output for mitigating the changes in power flows as well as relieves the probability of overload. The suggested algorithm prevents 
the power congestion as well as balances the load and renewable generations in the power systems. Moreover, this study also suggested a probabilistic technique to evaluate system uncertainty problems in power-systems by the generation rescheduling algorithm. From the analysis, the study stated that the suggested technique enhances the reliability of the power systems with higher penetration levels of RES (renewable energy sources)[50].

\section{ASO algorithm}

This study [51] constructed a RPO (reactive power optimization) technique of the power grid with higher penetration of solar as well as wind energy and provides new FASO (fast atom search optimization) algorithm for reaching set of solution to reactive power optimization problems. Further, this algorithm preserves prominent merits of avoiding premature convergence as well as higher searching efficacy when compared to original ASO algorithm that was employed for determining the generator's voltage, transformer's tap ratio, reactive output power of solar and wind energies as well as SVC (static VAR compensator). Moreover, the objective functions must be reduced to maintain the reliable and safe operations of power grid. The regulation capacities of PV (photovoltaic) stations and wind farms were evaluated on the basis of various weather conditions like solar irradiation and wind speed. Finally, the study verified that the suggested algorithm can meet requirements of optimal regulation and also can obtain the regulation schemes with more convergence speed as well as the convergence stability, when compare to prevailing methods.

\section{PSO-SSA Algorithm}

Several studies employed particle swarm optimization and salp swarm algorithm for obtaining high efficiency. In such way, in this study [52], PSO method was involved, in which the suggested system efficiently tracked MPP in the crucial environmental conditions such as partial shading of irradiance and temperature as well as larger fluctuations. The searching agents must be initialized on the basis of PSC variations. And this study [53] stated that GWO technique depicted improvised performance, as well as the output power oscillations are minimized by the integration $[54,55]$.

The photovoltaic (PV) system possibility was depicted after the evaluations. Additionally, the sliding mode was designed in the study [56] for the photovoltaic system due to the rapid change of the atmospheric conditions. Moreover, the gains of optimal SMC is identified by the particle swarm optimization algorithm[57].

The output voltage, which was introduced by the buck boost converter as well as it assures about better energy transfer. Further, the disadvantages such as partial shading was not allowed for generating maximum power. This algorithm with particle swarm optimization was utilized for overcoming these limitations as well as irradiations found in the study [58]. By the zeta converter, the solar photovoltaic output power was optimized, and with the step down device, some voltage would be regulated. Moreover, based on MRAC (model reference adaptive control), the design is similar to the conventional structure of PID. In order to reach the maximum power, the particle swarm optimization with more tracking speed as well as more tracking accuracy will be helpful with respect to the study. Finally, the simulation outcomes depicted that, higher efficacy was obtained via hybrid algorithms in every stages. In order to enhance the simulation process, the study utilized 3 phase linear transformer. Additionally, the batteries are charged without losing efficacy from the hybrid algorithm.

\section{RESEARCH GAP, CHALLENGES AND FUTURE DIRECTIONS}

It is with a significant importance to provide the more practical, critical and research gaps regarding the RES in power system control and operations [59]. The major issue with RES based power generation is the deviation in the production capacity at various time intervals, flexibility in the selection of location and operation control and the size of individual units. This section identifies the research gap from the existing literatures that enable to prepare various incentive mechanism to overcome the following problems. Some of the constrains in the implementation of solutions to these problems are the requirement of sophisticated information for controlling the load and the source, thermal loading limit and physical circuit constrains and requirement of thermal management for allowing the uninterrupted power flow. The disadvantages of solar PV are the huge installation and high commission cost and a storage process such as batteries. Further the solar PV comprise charge controller, inverter, battery storage and 
controllable loads. The main disadvantage of wind energy is that it is affected from huge intermittent nature and hence a proper storage mechanism based on artificial intelligence has to be adopted to reduce the overall cost.

In general, distributed generation comprise power converts to be utilized as an interface in between the connecting grid and the energy source. These power converters controls the machines present in these generators. Some of the main challenges in implementing the various solutions are discussed below.

During the change of voltage range in between the secondary and primary side to maintain the grid voltage within the desired range, the major drawback is the rise of higher cost and operation. Because of the intermittent nature of the solar energy, voltage could be increased or decreased rapidly. So the system needs to rise its operating time in order to keep the voltage within the range required. This in turn affect the system lifetime. In case of controlling grid voltage, one of the major limitation is the huge reaction time when compared with the vital power generation modification from PV systems. This reaction is an important aspect in the control design that considers the switching operations. Furthermore even for the short reaction handling case, the system would be translated to switching process of the devices thereby decreasing the lifetime. Apart from this the paper[34] found few unresolved topic and unexplored points which enhance the research regarding the solar and wind complementarity are incorporation of quality assured technique to prevent measurement error that interfere in the complementarity analysis, proper definition of reference metrics for allowing the comparison of various outputs from complementarity analysis. Further the climatic change impacts could directly affect the source complementarity.

Power generation, transmission followed by distribution operations of the conventional power systems over a wide geographical area were performed under an individual operator with few technical complexities. Due to huge increasing energy demand, the modern power systems are generally operating around the stability margins. If a major imbalance occurs the system do not possess adequate time for closing the deficit causing the cascading failures. Few important research gaps are mentioned below

Consideration of deviations of few significant parameters in the modern systems like frequency response, stability, inertia indices for the assessment of reliability. Hence the existing papers should investigate the capability of extensive parameters in enhancing the security and reliability of the modern power systems. Online coordination of various control methods in the power systems could enable the decrease of power outages. The existing papers must consider a smart grid features for adopting a protective function design which is free from cyber-attacks.

\section{RESEARCH GAP}

It is with a significant importance to provide the more practical, critical and research gaps regarding the RES in power system control and operations [59]. The major issue with RES based power generation is the deviation in the production capacity at various time intervals, flexibility in the selection of location and operation control and the size of individual units[60]. This section identifies the research gap from the existing literatures that enable to prepare various incentive mechanism to overcome the following problems[61]. Some of the constrains in the implementation of solutions to these problems are the requirement of sophisticated information for controlling the load and the source, thermal loading limit and physical circuit constrains and requirement of thermal management for allowing the uninterrupted power flow[62]. The disadvantages of solar PV are the huge installation and high commission cost and a storage process such as batteries[63]. Further the solar PV comprise charge controller, inverter, battery storage and controllable loads. The main disadvantage of wind energy is that it is affected from huge intermittent nature and hence a proper storage mechanism based on artificial intelligence has to be adopted to reduce the overall cost[64].

In general, distributed generation comprise power converts to be utilized as an interface in between the connecting grid and the energy source[49]. These power converters controls the machines present in these generators. Some of 
the main challenges in implementing the various solutions are discussed below.

During the change of voltage range in between the secondary and primary side to maintain the grid voltage within the desired range, the major drawback is the rise of higher cost and operation[65]. Because of the intermittent nature of the solar energy, voltage could be increased or decreased rapidly. So the system needs to rise its operating time in order to keep the voltage within the range required. This in turn affect the system lifetime. In case of controlling grid voltage, one of the major limitation is the huge reaction time when compared with the vital power generation modification from PV systems. This reaction is an important aspect in the control design that considers the switching operations. Furthermore even for the short reaction handling case, the system would be translated to switching process of the devices thereby decreasing the lifetime. Apart from this the paper[34] found few unresolved topic and unexplored points which enhance the research regarding the solar and wind complementarity are incorporation of quality assured technique to prevent measurement error that interfere in the complementarity analysis, proper definition of reference metrics for allowing the comparison of various outputs from complementarity analysis. Further the climatic change impacts could directly affect the source complementarity[66].

Power generation, transmission followed by distribution operations of the conventional power systems over a wide geographical area were performed under an individual operator with few technical complexities[67]. Due to huge increasing energy demand, the modern power systems are generally operating around the stability margins[68]. If a major imbalance occurs the system do not possess adequate time for closing the deficit causing the cascading failures. Few important research gaps are mentioned below

Consideration of deviations of few significant parameters in the modern systems like frequency response, stability, inertia indices for the assessment of reliability. Hence the existing papers should investigate the capability of extensive parameters in enhancing the security and reliability of the modern power systems. Online coordination of various control methods in the power systems could enable the decrease of power outages. The existing papers must consider a smart grid features for adopting a protective function design which is free from cyber-attacks.

Table 1: Survey on significant outcomes of existing studies

\begin{tabular}{|l|l|l|l|l|l|}
\hline S.No & Author & $\begin{array}{l}\text { Renewable Energy } \\
\text { Sources }\end{array}$ & $\begin{array}{l}\text { Area of the } \\
\text { study }\end{array}$ & Metric used & Significant outcomes \\
\hline 1 & {$[69]$} & Solar and Wind & $\begin{array}{l}\text { European } \\
\text { countries }\end{array}$ & $\begin{array}{l}\text { Linear least } \\
\text { square } \\
\text { regression } \\
\text { for } \\
\text { optimization }\end{array}$ & $\begin{array}{l}\text { The study observed an } \\
\text { optimum scenario of } \\
82 \% \text { of penetration rate } \\
\text { (26\% of solar and 74\% } \\
\text { of wind) of the } \\
\text { renewable sources. }\end{array}$ \\
\hline 2 & {$[70]$} & Solar and Wind & China & $\begin{array}{l}\text { Profit } \\
\text { coefficient, } \\
\text { synergy rate } \\
\text { and } \\
\text { coefficient } \\
\text { of variation }\end{array}$ & $\begin{array}{l}\text { The paper observed that } \\
\text { the integration of sub } \\
\text { regions might be } \\
\text { selected as alternatives } \\
\text { for making full } \\
\text { utilization of these } \\
\text { energies. }\end{array}$ \\
\hline
\end{tabular}




\begin{tabular}{|c|c|c|c|c|c|}
\hline 3 & [71] & Solar and Wind & America & $\begin{array}{l}\text { Pearson } \\
\text { correlation } \\
\text { coefficient } \\
\text { and } \\
\text { coefficient } \\
\text { of variance }\end{array}$ & $\begin{array}{l}\text { The paper found that } \\
\text { complementary peaks } \\
\text { of wind and solar } \\
\text { production appear on } \\
\text { daily and annual level }\end{array}$ \\
\hline 4 & [72] & Hydropower and solar & Poland & Ramp rate & $\begin{array}{l}\text { The results of the paper } \\
\text { depicted the possibility } \\
\text { of smoothing the } \\
\text { generation of solar } \\
\text { power by the integrated } \\
\text { usage with hydropower }\end{array}$ \\
\hline 5 & [73] & Hydropower and solar & China & $\begin{array}{l}\text { Annual solar } \\
\text { curtailment } \\
\text { and net } \\
\text { revenue } \\
\text { rates }\end{array}$ & $\begin{array}{l}\text { The integrated usage of } \\
\text { hydropower and solar } \\
\text { can resolve the issues } \\
\text { of solar variability. }\end{array}$ \\
\hline 6 & [74] & Hydropower and solar & Poland & $\begin{array}{l}\text { coefficient } \\
\text { of variance } \\
\text { and S.D }\end{array}$ & $\begin{array}{l}\text { The outcome } \\
\text { represented that } \\
\text { minimum hydropower } \\
\text { could compensate for } \\
\text { solar PV variability }\end{array}$ \\
\hline 7 & [75] & Solar and Wind & Europe & $\begin{array}{l}\text { Correlation } \\
\text { coefficient }\end{array}$ & $\begin{array}{l}\text { The paper observed a } \\
\text { degree of local } \\
\text { complementarity in } \\
\text { between solar and wind } \\
\text { sources in various } \\
\text { regions with the } \\
\text { hour-time scale }\end{array}$ \\
\hline 8 & [76] & Hydropower and Wind & Brazil & $\begin{array}{l}\text { Correlation } \\
\text { coefficient }\end{array}$ & $\begin{array}{l}\text { A huge level of } \\
\text { complementarity in } \\
\text { between the solar and } \\
\text { wind sources in the } \\
\text { region investigated }\end{array}$ \\
\hline 9 & [77] & Solar and Wind & Brazil & $\begin{array}{l}\text { Amplitude } \\
\text { related index } \\
\text { and time } \\
\text { related index }\end{array}$ & $\begin{array}{l}\text { The paper found that the } \\
\text { usage of hybridized } \\
\text { wind solar power } \\
\text { systems might be highly } \\
\text { efficient than individual } \\
\text { wind and solar system }\end{array}$ \\
\hline 10 & [78] & Solar and Wind & Australia & $\begin{array}{l}\text { Interquartile } \\
\text { range and } \\
\text { relative } \\
\text { coefficient } \\
\text { of variation }\end{array}$ & $\begin{array}{l}\text { The intermittency and } \\
\text { variability occurred by } \\
\text { the individual source } \\
\text { generation might be } \\
\text { strongly mitigated by } \\
\text { the integrated usage } \\
\text { with other sources. }\end{array}$ \\
\hline
\end{tabular}




\begin{tabular}{|c|c|c|c|c|c|}
\hline 11 & [79] & Solar and Wind & China & $\begin{array}{l}\text { Kendall } \\
\text { correlation } \\
\text { coefficient }\end{array}$ & $\begin{array}{l}\text { The paper observed that } \\
\text { northern and } \\
\text { northwestern regions } \\
\text { presented significant } \\
\text { solar and wind } \\
\text { complementarity }\end{array}$ \\
\hline 12 & [80] & Solar and Wind & Britian & $\begin{array}{l}\text { S.D and } \\
\text { Pearson } \\
\text { correlation } \\
\text { coefficient }\end{array}$ & $\begin{array}{l}\text { The study determined } \\
\text { that the regular } \\
\text { variability in the total } \\
\text { power is always } \\
\text { decreased by solar } \\
\text { incorporation. This } \\
\text { situation with minimum } \\
\text { seasonal variability is } \\
30 \% \text { of wind and } 70 \% \\
\text { of solar }\end{array}$ \\
\hline 13 & [81] & $\begin{array}{l}\text { Hydropower and wind } \\
\text { and hydro }\end{array}$ & brazil & $\begin{array}{l}\text { Cluster } \\
\text { analysis and } \\
\text { Pearson } \\
\text { coefficienct }\end{array}$ & $\begin{array}{l}\text { This study observed } \\
\text { that Brazillian wind } \\
\text { resource is highly } \\
\text { significant and } \\
\text { presented huge } \\
\text { complementarity with } \\
\text { hydropower resources }\end{array}$ \\
\hline 14 & [82] & Solar and hydropower & Italy & S.D & $\begin{array}{l}\text { This paper state that at } \\
\text { hourly scale, a high } \\
\text { share of hydropower } \\
\text { permits the reducing of } \\
\text { energy balance } \\
\text { variability. At daily and } \\
\text { monthly temporal scale, } \\
\text { opposite reaction occurs } \\
\text { due to low variability of } \\
\text { the solar power }\end{array}$ \\
\hline 15 & [83] & $\begin{array}{l}\text { Concentrated solar and } \\
\text { wind power }\end{array}$ & $\begin{array}{l}\text { The } \\
\text { southern } \\
\text { part of the } \\
\text { Iberian } \\
\text { Peninsula }\end{array}$ & S.D & $\begin{array}{l}\text { The study observed that } \\
\text { more benefits are } \\
\text { obtained in accordance } \\
\text { to power mix when } \\
\text { compared to single site } \\
\text { installation }\end{array}$ \\
\hline
\end{tabular}

\section{CONCLUSION}

Now a days power systems faces various ground breaking challenges to meet the growing demands of industries. Hence recent research focus on the renewable energy source to overcome the research gaps. This study emphasizes the barriers in installing wind and solar power systems with adoptable solutions. Further, the challenges of power system with respect to the non-linearized function is rectified by the artificial intelligence. This study also elaborated about the significance of AI algorithms in optimization of power system like forecasting, scheduling as well as control, etc. Moreover, certain articles like salp swarm optimization, Atom search optimization and Particle swarm optimization were examined in this article for enhancing the overall performance of power system. This study only examined the optimization analysis, but it also 
investigated several types of storage system for the improvisation of power system with respect to operation characteristics, application as well as cost. The future analysis deals with in-depth revision of the existing of the existing characteristics for further improvements of the performance.

\section{Declaration of Interest}

I Am Vinay Kumar Tatikayala Hereby State That The Manuscript Title Entitled "A Comprehensive Survey On The Impact Of Renewable Energy Sources In Power System Operation And Control" Submitted To Soft Computing, I Confirm That This Work Is Original And Has Not Been Published Elsewhere, Nor Is It Currently Under Consideration For Publication Elsewhere. And I Am Research Scholar in Department of Electrical Engineering, Madhav Institute of Technology and Science, Madhya Pradesh, India.

I'm the corresponding author of our paper, my contribution work on this paper is to Writing, developing, and reviewing the content of the manuscript. And my co-author Shishir Dixit work is to cite the figure, table and references. Equally I have done 50\% and my second author has done $50 \%$ of the work. We are the entire contributors of our paper. Any other third party people are not involved in this paper.

\section{REFERENCES}

[1] F. Nadeem, S. S. Hussain, P. K. Tiwari, A. K. Goswami, and T. S. Ustun, "Comparative review of energy storage systems, their roles, and impacts on future power systems," IEEE Access, vol. 7, pp. 4555-4585, 2018.

[2] V. Kharchenko, V. Gusarov, and V. Bolshev, "Reliable Electricity Generation in RES-Based Microgrids," in Handbook of Research on Smart Power System Operation and Control, ed: IGI Global, 2019, pp. 162-187.

[3] B. Kroposki, B. Johnson, Y. Zhang, V. Gevorgian, P. Denholm, B.-M. Hodge, et al., "Achieving a $100 \%$ renewable grid: Operating electric power systems with extremely high levels of variable renewable energy," IEEE Power and Energy Magazine, vol. 15, pp. 61-73, 2017.

[4] A. Saidi and B. Chellali, "Simulation and control of Solar Wind hybrid renewable power system," in 2017 6th International Conference on Systems and Control (ICSC), 2017, pp. 51-56.

[5] B. Vedik, R. Kumar, R. Deshmukh, S. Verma, and C. K. Shiva, "Renewable Energy-Based Load Frequency Stabilization of Interconnected Power Systems Using Quasi-Oppositional Dragonfly Algorithm," Journal of Control, Automation and Electrical Systems, vol. 32, pp. 227-243, 2021.

[6] D. W. Gao, Q. Wang, F. Zhang, X. Yang, Z. Huang, S. Ma, et al., "Application of AI techniques in monitoring and operation of power systems," Frontiers in Energy, vol. 13, pp. 71-85, 2019.

[7] Y. Liu, Z. Mao, H. Li, K. S. Shetye, and T. J. Overbye, "Integration of Renewable Generators in Synthetic Electric Grids for Dynamic Analysis," arXiv preprint arXiv:2101.02319, 2021.

[8] N. Javaid, I. Ullah, M. Akbar, Z. Iqbal, F. A. Khan, N. Alrajeh, et al., "An intelligent load management system with renewable energy integration for smart homes," IEEE access, vol. 5, pp. 13587-13600, 2017.

[9] B. K. Bose, "Power electronics, smart grid, and renewable energy systems," Proceedings of the IEEE, vol. 105, pp. 2011-2018, 2017.

[10] Z. Abdmouleh, A. Gastli, L. BenBrahim, M. Haouari, and N. A. AlEmadi, "Review of optimization techniques applied for the integration of distributed generation from renewable energy sources," Renewable Energy, vol. 113, pp. 266280, 2017.

[11] T. Adefarati and R. C. Bansal, "Reliability, economic and environmental analysis of a microgrid system in the presence of renewable energy resources," Applied energy, vol. 236, pp. 1089-1114, 2019.

[12] J. D. Jenkins, Z. Zhou, R. Ponciroli, R. Vilim, F. Ganda, F. de Sisternes, et al., "The benefits of nuclear flexibility in 
power system operations with renewable energy," Applied energy, vol. 222, pp. 872-884, 2018.

[13] T. Adefarati and R. Bansal, "Reliability and economic assessment of a microgrid power system with the integration of renewable energy resources," Applied Energy, vol. 206, pp. 911-933, 2017.

[14] H. Golpîra, A. Atarodi, S. Amini, A. R. Messina, B. Francois, and H. Bevrani, "Optimal energy storage system-based virtual inertia placement: a frequency stability point of view," IEEE Transactions on Power Systems, vol. 35, pp. 4824-4835, 2020.

[15] T. Kerdphol, F. S. Rahman, Y. Mitani, K. Hongesombut, and S. Küfeoğlu, "Virtual inertia control-based model predictive control for microgrid frequency stabilization considering high renewable energy integration," Sustainability, vol. 9, p. 773, 2017.

[16] P. Du and W. Li, "Frequency response impact of integration of HVDC into a low-inertia AC power grid," IEEE Transactions on Power Systems, 2020.

[17] K. Y. Yap, C. R. Sarimuthu, and J. M.Y. Lim, "Virtual inertia-based inverters for mitigating frequency instability in grid-connected renewable energy system: A review," Applied Sciences, vol. 9, p. 5300, 2019.

[18] T. Kerdphol, F. S. Rahman, and Y. Mitani, "Virtual inertia control application to enhance frequency stability of interconnected power systems with high renewable energy penetration," Energies, vol. 11, p. 981, 2018.

[19] S. M. Said, M. Aly, B. Hartmann, and E. A. Mohamed, "Coordinated fuzzy logic-based virtual inertia controller and frequency relay scheme for reliable operation of low-inertia power system," IET Renewable Power Generation, 2021.

[20] L. Mehigan, D. Al Kez, S. Collins, A. Foley, B. Ó'Gallachóir, and P. Deane, "Renewables in the European power system and the impact on system rotational inertia," Energy, vol. 203, p. 117776, 2020

[21] K. S. Ratnam, K. Palanisamy, and G. Yang, "Future low-inertia power systems: Requirements, issues, and
solutions-A review," Renewable and Sustainable Energy Reviews, vol. 124, p. 109773, 2020.

[22] T. Kerdphol, F. S. Rahman, Y. Mitani, M. Watanabe, and S. K. Küfeoğlu, "Robust virtual inertia control of an islanded microgrid considering high penetration of renewable energy," IEEE Access, vol. 6, pp. 625-636, 2017.

[23] W. J. Farmer and A. J. Rix, "Optimising power system frequency stability using virtual inertia from inverter-based renewable energy generation," IET Renewable Power Generation, vol. 14, pp. 2820-2829, 2020.

[24] H. R. Chamorro, F. R. S. Sevilla, F. Gonzalez-Longatt, K. Rouzbehi, H. Chavez, and V. K. Sood, "Innovative primary frequency control in lowinertia power systems based on widearea RoCoF sharing," IET Energy Systems Integration, vol. 2, pp. 151160, 2020

[25] A. O. Aluko, D. G. Dorrell, R. Pillay Carpanen, and E. E. Ojo, "Heuristic optimization of virtual inertia control in grid-connected wind energy conversion systems for frequency support in a restructured environment," Energies, vol. 13, p. 564, 2020

[26] X. Deng and T. Lv, "Power system planning with increasing variable renewable energy: A review of optimization models," Journal of Cleaner Production, vol. 246, p. 118962, 2020.

[27] A. Fernández-Guillamón, J. I. Sarasúa, M. Chazarra, A. Vigueras-Rodríguez, D. Fernández-Muñoz, and Á. MolinaGarcía, "Frequency control analysis based on unit commitment schemes with high wind power integration: A Spanish isolated power system case study," International Journal of Electrical Power \& Energy Systems, vol. 121, p. 106044, 2020.

[28] N. Hosseinzadeh, A. Aziz, A. Mahmud, A. Gargoom, and M. Rabbani, "Voltage Stability of Power Systems with Renewable-Energy Inverter-Based Generators: A Review. Electronics 2021, 10, 115," ed: s Note: MDPI stays neu-tral with regard to jurisdictional clai-ms in ..., 2021. 
[29] H. C. Gils, Y. Scholz, T. Pregger, D. L. de Tena, and D. Heide, "Integrated modelling of variable renewable energy-based power supply in Europe," Energy, vol. 123, pp. 173 188, 2017.

[30] F. R. Badal, P. Das, S. K. Sarker, and S. K. Das, "A survey on control issues in renewable energy integration and microgrid," Protection and Control of Modern Power Systems, vol. 4, pp. 127, 2019.

[31] H. Zsiborács, N. H. Baranyai, A. Vincze, L. Zentkó, Z. Birkner, K. Máté, et al., "Intermittent renewable energy sources: The role of energy storage in the european power system of 2040," Electronics, vol. 8, p. 729, 2019.

[32] L. M. Putranto and E. Y. Pramono, "Maximum penetration determination of variable renewable energy generation: A case in Java-Bali power systems," Renewable Energy, vol. 163, pp. 561-570, 2021.

[33] T. Salameh, M. A. Abdelkareem, A. Olabi, E. T. Sayed, M. Al-Chaderchi, and H. Rezk, "Integrated standalone hybrid solar PV, fuel cell and diesel generator power system for battery or supercapacitor storage systems in Khorfakkan, United Arab Emirates," International Journal of Hydrogen Energy, vol. 46, pp. 6014-6027, 2021.

[34] F. Weschenfelder, G. d. N. P. Leite, A. C. A. da Costa, O. de Castro Vilela, C. M. Ribeiro, A. A. V. Ochoa, et al., "A review on the complementarity between grid-connected solar and wind power systems," Journal of Cleaner Production, vol. 257, p. 120617, 2020.

[35] O. Gandhi, D. S. Kumar, C. D. Rodríguez-Gallegos, and D. Srinivasan, "Review of power system impacts at high PV penetration Part I: Factors limiting PV penetration," Solar Energy, vol. 210, pp. 181-201, 2020.

[36] M. Tavakoli, E. Pouresmaeil, J. Adabi, R. Godina, and J. P. Catalão, "Loadfrequency control in a multi-source power system connected to wind farms through multi terminal HVDC systems," Computers \& Operations Research, vol. 96, pp. 305-315, 2018.
[37] A. Aziz, A. T. Oo, and A. Stojcevski, "Analysis of frequency sensitive wind plant penetration effect on load frequency control of hybrid power system," International Journal of Electrical Power \& Energy Systems, vol. 99, pp. 603-617, 2018.

[38] N. E. Y. Kouba, M. Menaa, M. Hasni and M. Boudour, "LFC enhancement concerning large wind power integration using new optimised PID controller and RFBs," IET Generation, Transmission \& Distribution, vol. 10, pp. 4065-4077, 2016.

[39] A. Rahman, L. C. Saikia, and N. Sinha, "AGC of dish-Stirling solar thermal integrated thermal system with biogeography based optimised three degree of freedom PID controller," IET Renewable Power Generation, vol. 10, pp. 1161-1170, 2016.

[40] S. Kumar, R. Saket, D. K. Dheer, J. Holm-Nielsen, and P. Sanjeevikumar, "Reliability enhancement of electrical power system including impacts of renewable energy sources: a comprehensive review," IET Generation, Transmission \& Distribution, vol. 14, pp. 1799-1815, 2020.

[41] T. Ma and M. S. Javed, "Integrated sizing of hybrid PV-wind-battery system for remote island considering the saturation of each renewable energy resource," Energy conversion and management, vol. 182, pp. 178190, 2019.

[42] R. Hemmati, H. Saboori, and M. A. Jirdehi, "Stochastic planning and scheduling of energy storage systems for congestion management in electric power systems including renewable energy resources," Energy, vol. 133, pp. 380-387, 2017.

[43] P. Das, P. Mathuria, R. Bhakar, J. Mathur, A. Kanudia, and A. Singh, "Flexibility requirement for largescale renewable energy integration in Indian power system: Technology, policy and modeling options," Energy Strategy Reviews, vol. 29, p. 100482, 2020.

[44] C. Ghenai, T. Salameh, and A. Merabet, "Technico-economic analysis of off grid solar PV/Fuel cell energy system for residential community in desert region," 
International Journal of Hydrogen Energy, vol. 45, pp. 11460-11470, 2020.

[45] R. Verzijlbergh, L. De Vries, G. Dijkema, and P. Herder, "Institutional challenges caused by the integration of renewable energy sources in the European electricity sector," Renewable and Sustainable Energy Reviews, vol. 75, pp. 660-667, 2017.

[46] S. Collins, P. Deane, B. Ó. Gallachóir, S. Pfenninger, and I. Staffell, "Impacts of inter-annual wind and solar variations on the European power system," Joule, vol. 2, pp. 2076-2090, 2018.

[47] T. Adefarati and R. Bansal, "Reliability assessment of distribution system with the integration of renewable distributed generation," Applied energy, vol. 185, pp. 158-171, 2017.

[48] A. Rathore and N. Patidar, "Reliability assessment using probabilistic modelling of pumped storage hydro plant with PV-Wind based standalone microgrid," International Journal of Electrical Power \& Energy Systems, vol. 106, pp. 17-32, 2019.

[49] M. Fan, K. Sun, D. Lane, W. Gu, Z. Li, and F. Zhang, "A novel generation rescheduling algorithm to improve power system reliability with high renewable energy penetration," IEEE Transactions on Power Systems, vol. 33, pp. 3349-3357, 2018.

[50] H. M. Hasanien, "Whale optimisation algorithm for automatic generation control of interconnected modern power systems including renewable energy sources," IET Generation, Transmission \& Distribution, vol. 12, pp. 607-614, 2017.

[51] F. Zeng and H. Shu, "Fast Atom Search Algorithm for Reactive Power Optimization of Power Grid with High-Penetration Wind and Solar Energies," Mathematical Problems in Engineering, vol. 2020, 2020.

[52] S. S. Dash, S. Padmanaban, and P. K. Morati, "Maximum power point tracking implementation by Dspace controller integrated through Z-Source inverter using particle swarm optimization technique for photovoltaic applications," Applied Sciences, vol. 8, p. 145, 2018.
[53] A. M. Eltamaly and H. M. Farh, "Dynamic global maximum power point tracking of the PV systems under variant partial shading using hybrid GWO-FLC," Solar Energy, vol. 177, pp. 306-316, 2019.

[54] H. Tapri, "An improved perturbation and observation in mppt control using buck-boost converter in solar panel," Universiti Tun Hussein Onn Malaysia, 2019.

[55] A. Yoganandini and G. Anitha, "A modified particle swarm optimization algorithm to enhance MPPT in the PV array," International Journal of Electrical and Computer Engineering, vol. 10, p. 5001, 2020.

[56] A. Harrag and S. Messalti, "PSObased SMC variable step size $\mathrm{P} \& \mathrm{O}$ MPPT controller for PV systems under fast changing atmospheric conditions," International Journal of Numerical Modelling: Electronic Networks, Devices and Fields, vol. 32, p. e2603, 2019.

[57] A. Ibrahim, R. Aboelsaud, and S. Obukhov, "Improved particle swarm optimization for global maximum power point tracking of partially shaded PV array," Electrical Engineering, vol. 101, pp. 443-455, 2019.

[58] T. Winarno, L. N. Palupi, A. Pracoyo, and L. Ardhenta, "MPPT control of PV array based on PSO and adaptive controller," Telkomnika, vol. 18, 2020.

[59] S. Impram, S. V. Nese, and B. Oral, "Challenges of renewable energy penetration on power system flexibility: A survey," Energy Strategy Reviews, vol. 31, p. 100539, 2020.

[60] G. Aquila, E. de Oliveira Pamplona, A. R. de Queiroz, P. R. Junior, and M. N. Fonseca, "An overview of incentive policies for the expansion of renewable energy generation in electricity power systems and the Brazilian experience," Renewable and Sustainable Energy Reviews, vol. 70, pp. 1090-1098, 2017.

[61] M. A. Basit, S. Dilshad, R. Badar, and S. M. Sami ur Rehman, "Limitations, challenges, and solution approaches in grid-connected renewable energy systems," International Journal of Energy Research, vol. 44, pp. 41324162, 2020. 
[62] S. Martinez, G. Michaux, P. Salagnac, and J.-L. Bouvier, "Micro-combined heat and power systems (micro-CHP) based on renewable energy sources," Energy Conversion and Management, vol. 154, pp. 262-285, 2017.

[63] N. Bizon and P. Thounthong, "Energy efficiency and fuel economy of a fuel cell/renewable energy sources hybrid power system with the load-following control of the fueling regulators," Mathematics, vol. 8, p. 151, 2020.

[64] M. Hannan, S. Y. Tan, A. Q. AlShetwi, K. P. Jern, and R. Begum, "Optimized controller for renewable energy sources integration into microgrid: Functions, constraints and suggestions," Journal of Cleaner Production, vol. 256, p. 120419, 2020.

[65] V. Telukunta, J. Pradhan, A. Agrawal, M. Singh, and S. G. Srivani, "Protection challenges under bulk penetration of renewable energy resources in power systems: A review," CSEE journal of power and energy systems, vol. 3, pp. 365-379, 2017.

[66] R. H. Wiser, A. Mills, J. Seel, T. Levin, and A. Botterud, "Impacts of variable renewable energy on bulk power system assets, pricing, and costs," Lawrence Berkeley National Lab.(LBNL), Berkeley, CA (United States)2017.

[67] M. Dreidy, H. Mokhlis, and S. Mekhilef, "Inertia response and frequency control techniques for renewable energy sources: A review," Renewable and sustainable energy reviews, vol. 69, pp. 144-155, 2017.

[68] S. Singh, A. R. Gautam, and D. Fulwani, "Constant power loads and their effects in DC distributed power systems: A review," Renewable and Sustainable Energy Reviews, vol. 72, pp. 407-421, 2017.

[69] W. Zappa and M. Van Den Broek, "Analysing the potential of integrating wind and solar power in Europe using spatial optimisation under various scenarios," Renewable and Sustainable Energy Reviews, vol. 94, pp. 1192-1216, 2018.

[70] H. Zhang, Y. Cao, Y. Zhang, and V. Terzija, "Quantitative synergy assessment of regional wind-solar energy resources based on MERRA reanalysis data," Applied energy, vol. 216, pp. 172-182, 2018.

[71] J. H. Slusarewicz and D. S. Cohan, "Assessing solar and wind complementarity in Texas," Renewables: Wind, Water, and Solar, vol. 5, pp. 1-13, 2018.

[72] J. Jurasz and B. Ciapała, "Integrating photovoltaics into energy systems by using a run-off-river power plant with pondage to smooth energy exchange with the power gird," Applied energy, vol. 198, pp. 21-35, 2017.

[73] W. Fang, Q. Huang, S. Huang, J. Yang, E. Meng, and Y. Li, "Optimal sizing of utility-scale photovoltaic power generation complementarily operating with hydropower: a case study of the world's largest hydrophotovoltaic plant," Energy Conversion and Management, vol. 136, pp. 161-172, 2017.

[74] J. Jurasz, M. Wdowikowski, B. Kaźmierczak, and P. Dąbek, "Temporal and spatial complementarity of wind and solar resources in Lower Silesia (Poland)," in E3S web of conferences, 2017, p. 00074 .

[75] M. M. Miglietta, T. Huld, and F. Monforti-Ferrario, "Local complementarity of wind and solar energy resources over Europe: an assessment study from a meteorological perspective," Journal of Applied Meteorology and Climatology, vol. 56, pp. 217-234, 2017.

[76] M. P. Cantão, M. R. Bessa, R. Bettega, D. H. Detzel, and J. M. Lima, "Evaluation of hydro-wind complementarity in the Brazilian territory by means of correlation maps," Renewable Energy, vol. 101, pp. 1215-1225, 2017.

[77] G. Pianezzola, A. Krenzinger, and F. A. C. Vega, "Complementarity maps of wind and solar energy resources for Rio Grande do Sul, Brazil," Energy and power engineering [recurso eletrônico].[Wuhan, China]. Vol. 9, no. 9 (2017), p. 489-504, 2017.

[78] A. A. Prasad, R. A. Taylor, and M. Kay, "Assessment of solar and wind resource synergy in Australia," Applied Energy, vol. 190, pp. 354-367, 2017. 
[79] L. Xu, Z. Wang, and Y. Liu, "The spatial and temporal variation features of wind-sun complementarity in China," Energy Conversion and Management, vol. 154, pp. 138-148, 2017.

[80] P. E. Bett and H. E. Thornton, "The climatological relationships between wind and solar energy supply in Britain," Renewable Energy, vol. 87, pp. 96-110, 2016.

[81] A. R. Silva, F. M. Pimenta, A. T. Assireu, and M. H. C. Spyrides, "Complementarity of Brazil' s hydro and offshore wind power," Renewable and Sustainable Energy Reviews, vol. 56, pp. 413-427, 2016.

[82] B. François, B. Hingray, D. Raynaud, M. Borga, and J. Creutin, "Increasing climate-related-energy penetration by integrating run-of-the river hydropower to wind/solar mix," Renewable Energy, vol. 87, pp. 686696, 2016.

[83] N. S. Thomaidis, F. J. SantosAlamillos, D. Pozo-Vázquez, and J. Usaola-García, "Optimal management of wind and solar energy resources," Computers \& Operations Research, vol. 66, pp. 284-291, 2016. 
Figures

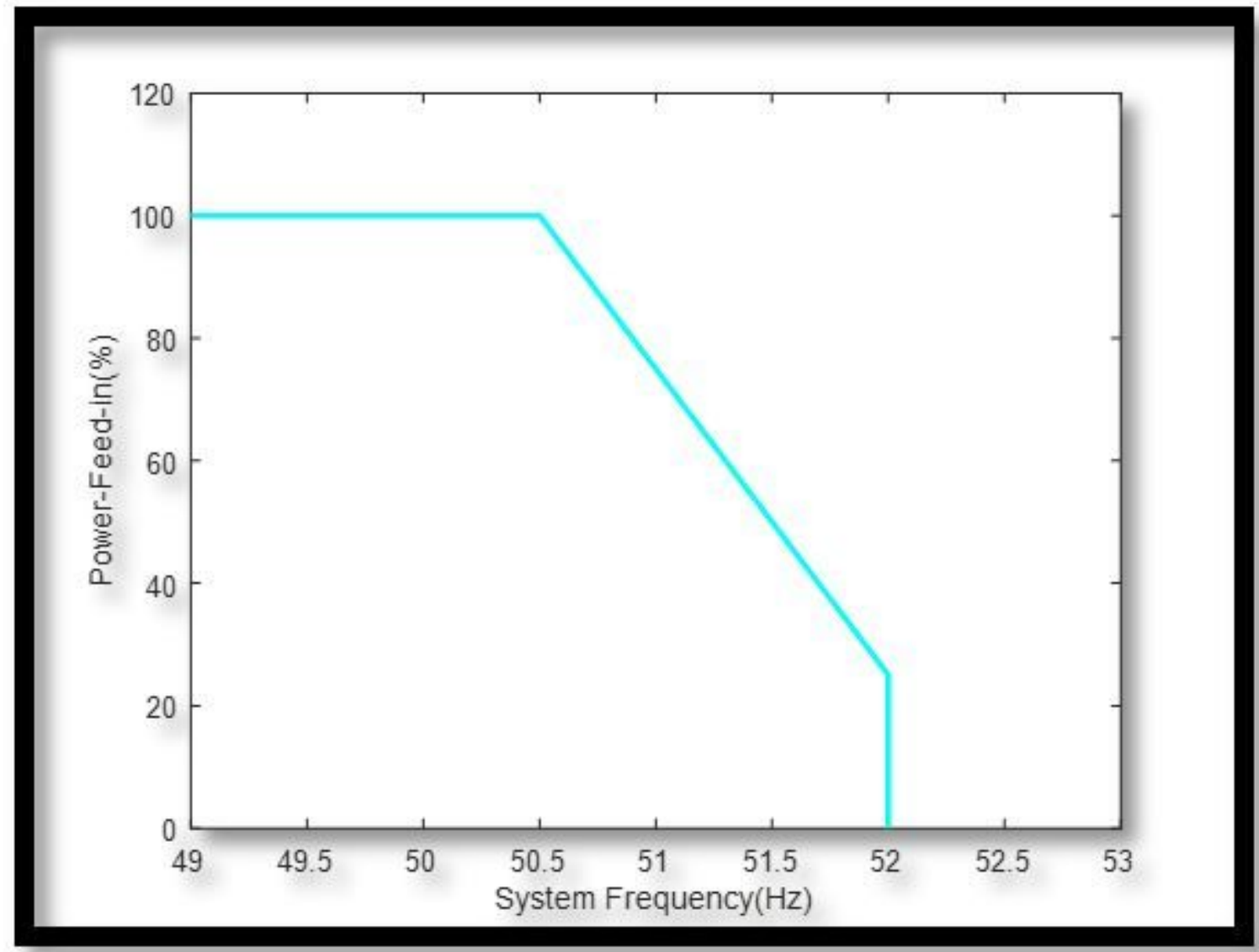

Figure 1

Power curtailment during the over-frequency for renewable power plants 